\section{APILAMIENTOS EN FISAC, JUEGOS DE CONSTRUCCION DE LA FORMA} FISAC'S STACKS, PLAYING CONSTRUCTION GAMES WITH FORM

Ricardo Sánchez Lampreave
RESUMEN Ciertas formas geométricas han encarnado, en manos de los arquitectos, valores determinantes para el entendimiento del devenir de la Arquitectura. Asociados al ideal de perfección, la pureza de los cuerpos geométricos simples late en los grandes edificios de la Historia. Los métodos pedagógicos de Froebel y sus seguidores pusieron a jugar a futuros artistas y arquitectos que dejaron atrapada por su memoriala la posibilidad de construir apilando piezas, una sobre otra. Algunas de las lineas mas esquemá-

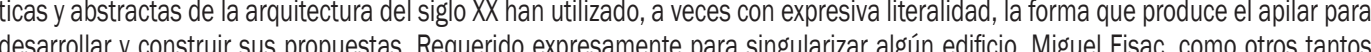
arquitectos, también los más puintes hoy, tampoco escapóa este "formalismo escultórico" La construcción de la forma arquitectónica, tantas veces inequivoco juego contra la gravedad, tiene en el apilamiento de piezas una de sus estrategegias más reconocibles. PALABRAS CLAVE apilamiento; Fisac; Froebel; forma; construcción

SUMMARY Certain geometric forms have incarnated in the hands of architects, determining values for understanding the future of Architecture. Associated with the ideal of perfection, the purity of simple geometric bodies shines through in the great buildings of
History. The pedagogical methods of Froebel and his followers lef future artists and architects play, thereby memorising the possibility of constructing stacked pieces, one upon another. Some of the most schematic and abstract lines of 20th century architecture have, sometimes with expressive literality, used the stacked form to develop and construct their proposalls. Expressily required to

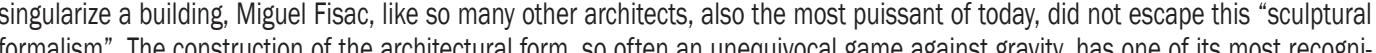
zable strategies in stacking.
KEY wORDS stacking

Persona de contacto / Corresponding author: ricardo@lampreave.es. Escuela de Ingeniería y Arquitectura. Universidad de Zaragoza

\section{"DONES Y OCUPACIONES"}

o parece cabal dudar de cómo ciertas formas goometricas han encarnado, en manos de os arquitectos, valores determinantes para entendimiento de cuanto le ha venido sucediendo a la de una moderna Le Corbusier, paradigmático ejemplo la pureza de los cuerpos geométricos simples ya estaba latente en los grandes edificios de la antiguedad romana². Desde que retornara de su viaje a Oriente -cuando escribio exaltado a su amigo Wililiam Ritter desde Italia, a finales de 1911: "Clamo por la geometía elemental; estoy poseido por el color blanco, el cubo, la estera, el clilindro y la piramide. Los prismas se elevan y se equilibran entre si,

estableciendo ritmos...bajo el sol del mediodia los cubos se aplanan convirtiéndose en una superficie, en el crepúsculo un arco iris parece elevarse de las formas. Por las mañanas son reales, arrojan luz y sombra y se pertilan claramente como un dibujo..." ${ }^{\prime \prime}$, ya no abandonó a lo largo de su vida la defensa de los volúmenes elementales, "les formes que les yeux voient $t^{4}$. No fue el único, ni tampoco el primero en advertirio. Frank Lloyd Wright tuvo a la edad de nueve años, gracias a su madre, las cajas de piezas de madera de Froebel, con sus "dones y ocupaciones" ral de sus posibilidades formalivas. En su Autobiografla los cita indirectamente - "For several years I sat at the little a formales en la vivienda colectiva" y "Las formas onduladas que rigen un buen numero de sus obras y proyectos. Veanse por ejemplo los capitulos "Apriorismos formales en la vivienda colectiva" y "Las formas onduladas como tormas aporticas" en Cantel,

2. Recuérdese su conociddo dibujo de "la lección de Roma", una Roma Imperial coronada por un cilindro, una pirámide, un cubo, un prisma de base cuadrad

3. Véase Gregh, Eleanor: "The Domino Idea". En Oppositionn n 15/16, invierno/primavera 1979. Nueva York: Institut for Architecture and Urban Studies IAUS,

4. En Le Corbusier et Pierre Jeanneret. Oeuure complète. 1910-1929. Zúrich: Les Éditions d'Arrchitecture, 1974, p. 33

5. Diversos autores dan noticia de ello. Véanse Alofsin, Anthony: Frank Lloyd Wright. The Lost Years, 1910-1922: A Study of Influence. Chicago: University of Chicago Press, 1993, p. 359, y Hersey, George: Architecture and Geometry in the Age of the Baroque. Chicago: University of Chicago Press. 2000, p. 205. También de su posterior repercusión en el método compositivo de sus primeras casas. En castellano, con expresivos esquemas de composición, Baker, Geoffree, 


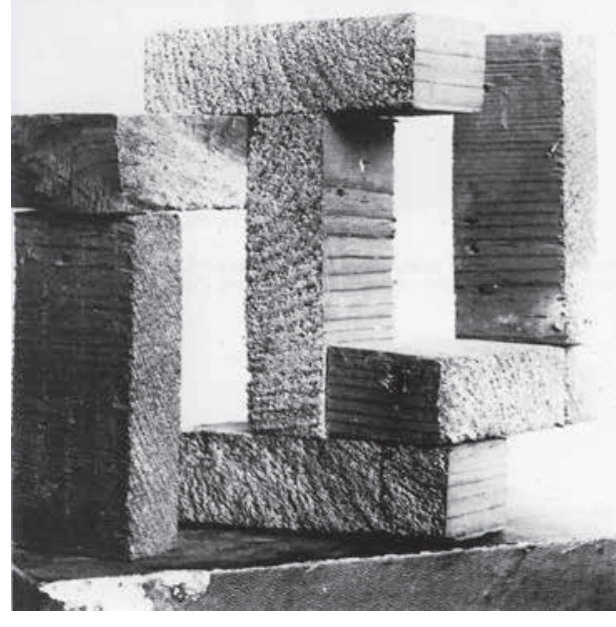

1. Aleksandr Rodchenko, Construcción de distancias, c.1920.

2. Nicolaj Ladouskji,
de laboratorio, 1919 .

3. Walter Gropius, Monumento a los cádos de marzo en el cementerio de Weimar, c.1921, y Karr Schmidt- Rottluff, detalle de la Columna de la oración, pro-
yecto para la "Casa del Cielo" de Bruno Taut, 1919.

Kindergarten table-top... and played... with the cube, the sphere and the triangle-these smooth wooden maple blocks... All are in my fingers to this day..."6-, explicando
cómo aprendió la geometría de la arquitectura jugando como aprendió la geometría de la arquitectura jugando en el kindergatten. Asociadas al ideal de perfección, su utilización, por mas que denotara sentido práctico, siempre exigio el esfuerzo de sintesis necesario para lograr considerasen extraídas de las leyes más profundas del mundo físico, en cuanto formas se oponían a la naturamundo fís

Poseedor de métodos pedagógicos derivados de de Froebel', el constructivismo ruso estableció los límites formales del juego. La serie Por el principio de formas guales, de 1020-21, pen ilo anotar a Aleksander Rodchenko en el borrador de su autobiografia. "Estas son las va experimench Excepcionalmente pas he elaborado por da expe ley de a racionalidad de formas aplicadas, de su dor a la ley de la racionallad de formas aplicadas, de su a base de formas idénticas es posible constrir estucturas

variadas, sistemas diversos, tipos y aplicaciones"s. De la número 14 (figura 1) escribió: "... se admite el principio de solución del espacio con formas iguales por su anchura y espesor, sin tomar en cuenta su longitud. Se admite e principio de la maxima salida de la tierra hacia el espacio sin desvincularse de ella siendo una estructura terrestre Tal como María Teresa Muñoz alijo de Mies, se podría pensar que Rodchenko diseña uniones y no partes"s. En el los "co purto de la construcción de la forma, otro de ros "Constructores" de la arquitectura sovetica, Nicolaj Ladovskij, companero de estudios de Melnikov, con e que siguí coincidiendo después, en 1918, en el labora-

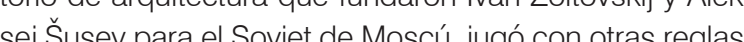
Jadoseriis Ladísticos siempre dirigió su atención hacia los problemas De hecho, dento de la comisín del Narompros. uno de los promo de la comision del Nakrompros, fue estudio de los problemas retativo a la sinesis entre pintura de marco de una exposición

6. Las sucesivas revisiones y ampliaciones de la primera edición de 1932 fueron estableciendo notables differencias entre ellas. Hay una somera descripción de estoos cambios en la presentación de Jose Avendaño de la edición española de 1998 de El Croquis Editorial (Autobiograrifía 1867 (1944). Traducida por ê

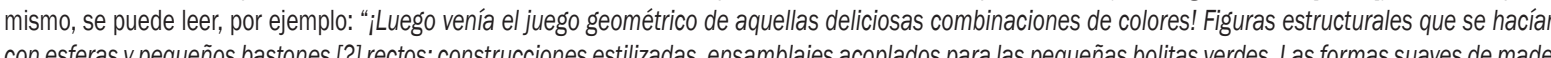

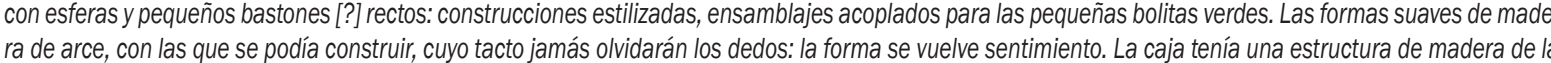

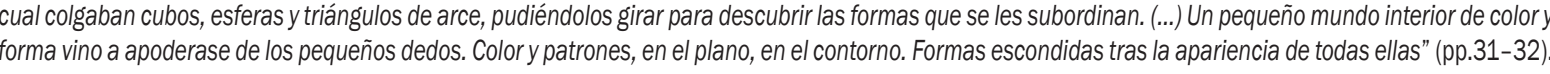
7. Para a jemplificar sintomáticamente el titulo de su libro, Juan Bordes lleva a la cubierta la caja de construcciones de origen ruso Epitokocka, capaz de plantear

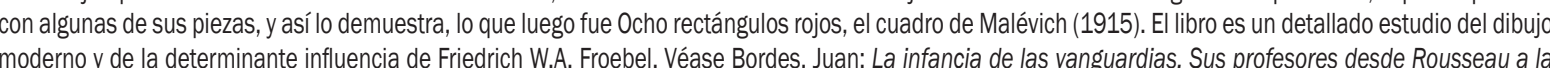

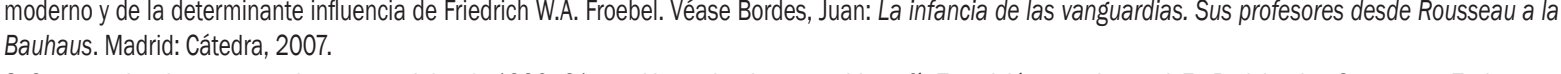

8. Comentario a las construcciones espaciales de 1920-21, en el borrador de su autobiografría Transición experimental. En Rodchenko-Stepanova: Todo es un

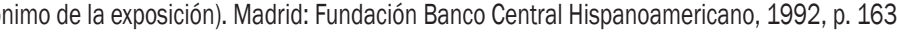

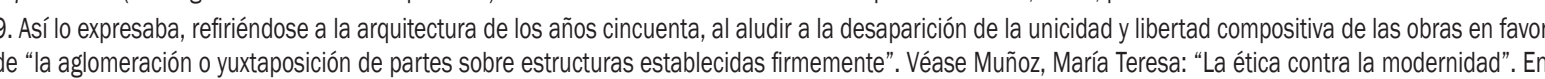
Arquitecturas bis no $n^{\circ} 27$, marzo-abril 1979. Barcelona: La Gaya Ciencia, pp. 9-15.
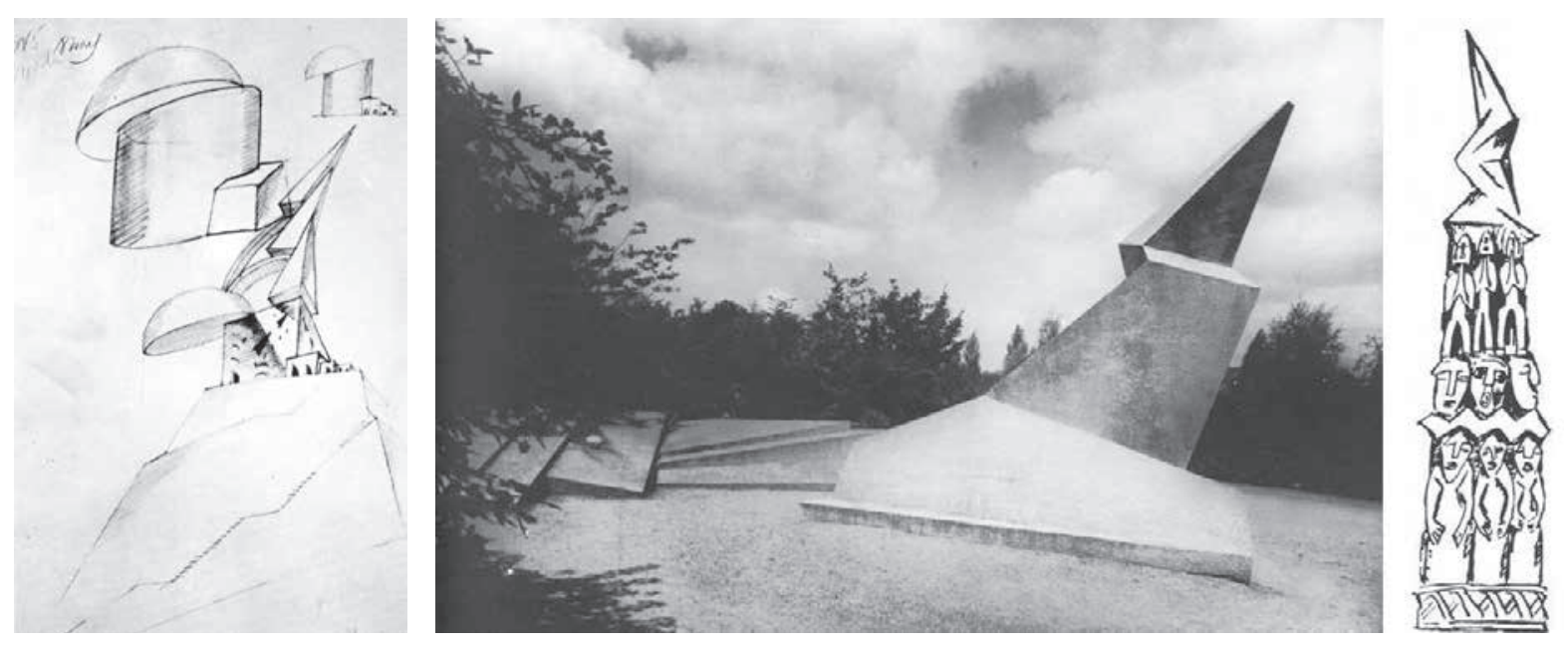

de trabajos del grupo, su "proyecto experimental de una casa para una comuna", estaba acompañado de un breve texto escrito a lápiz sobre una hoja pegada al panel que bién deben ser realizados en arquitectura. Los antiguos construyeron prodigios con el trabajo servil de las masas, siendo su elemento más importante la calidad del trabajo. Los prodigios arquitectónicos de la epoca actual, los que se moverán en el espacio, serán construidos con el arte y el intelecto, y deberá ser la calidad de la inteligencia su elemento más importante. El espacio, y no la piedra, es e material propio de la arquicoclua, y y toma escullonca debe estar al servicio de la espacialidad en arquitectura. A

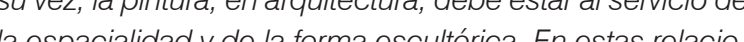
la espacianlad y de la forma escullonica. En estas relaciores reside la esencia de la shinesis en arquilectura". Sus prict de sus composios isterimentando con diversos voĺmenes geométicos (paralepípedos, esters

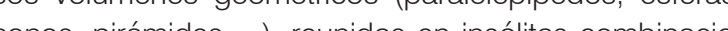
nes para crear complicadas composiciones dinámicas, muchas de ellas extendiéndose hacia lo alto (fivina 2). Son prácticamente las mismas fechas en las que Solter propius presenté una expresionista propus que alter Groplus presento una expresionsta propuesta eriado victorioso", convocado por los sindicatos para conmemorar el asesinato de nurve trabajores para intento de golpe de Estado de Kapp en marzo de 1920 $y$ en cuyos funerales tomaron parte los estudiantes anotaba los principios del credo creativo del primer racionalismo: "La técnica hace prodigios. Los prodigios tam-

Bauhaus. Como prueba de su todavía vigente fe expresionista, Gropius estaba escribiendo entonces en su texto "Neues Bauen" de 1920. "El sentimiento es la fuente de la invencion, la fuerza creativa de la proyectación y, pronto de la forma" "1, unas palabras que luego puso en práctica Johannes Itten en su curso preliminar de la Bauhaus. No obstante, su proyecto parece inspirado en el final de la columna de Karl Schmidt-Rottluff (figura 3) -uno de los estudiantes de arquitectura fundadores de Die Brückepensada para una casa de Bruno Taut, toda vez que fue colicada en el primer número de la revista Bauen.

Con la analogía que propicia la abrumadora descripción folográlica del taller de Brancusi-repleto de piezas como los que colm apan cabe parangonar que para la arquitectua modema las desgranadas unidades de sus programas se convitieron muchas veces on la herramienta que permith adecur su forma a lo que debiera alojar, segregando los distintos usos y especializando volumenes hasta in con ticulación del proyecto en elementos independientes. extrañamiento máximo suponí la independencia forma de usos entre los distintos cuerpos, de modo que y de usos entrésticamente se produjeran interferencias entre ellos. Así, cada edificio adoptaba la fomay las dnecesitara, y ante la inexistencia de rela-

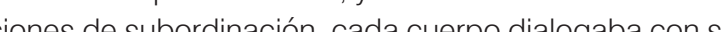
opuesto o contiguo en condiciones de igualdad Ésta es la razón de que prosperara el apilar para construr

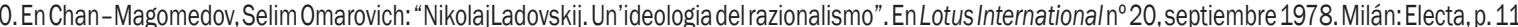
11. Véase Pehnt, Wolfgang: "Gropius romantico". En Rassegnna no 15, septiembre 1983 (Walter Gropius 1907/1934). Bolonia: CIPIA, pp. 27-36.

12. Aparentemente porque, tal como explicó Ángel Gonzzález "sin brusqueddad, casi sin esfuerzo, como ondas o reflejos en un estanque"), Brancusis sólo turo voluntad de arreglar y combinar piezas mediante unos primeros arreglos con lo que llamó " "grupos móviles", consistentes en propuestas de combinación de distintas piezas. Especialmente ilustrativa de esta posibilidad de apilamientos variados es la denominada Lenfant au monde. Véase González García, Ánge 


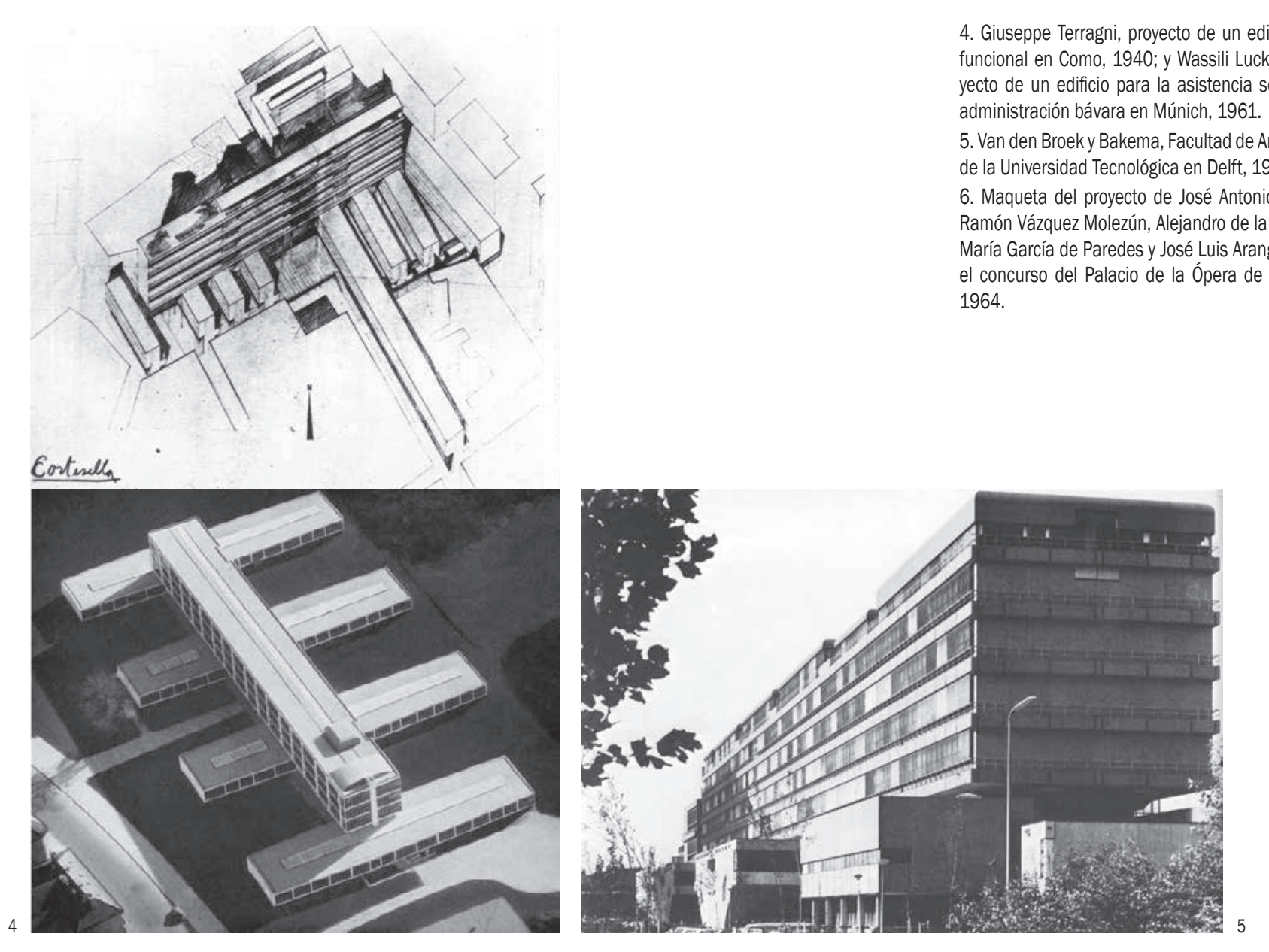

formas, como demuestra que a lo largo del siglo pasado se sucedieran ininterrumpidamente procederes y construcciones semejantes.

La premisa formal contraria, la utilización de estructuras predeterminadas ajenas a cualquier desorden compositivo, puede ejemplificarse con el conocido "botelero" de viviendas apiladas y macladas que compuso Le Corbusier con piezas de madera para explicar el principio ormal de sus Unités.

Giuseppe Terragni, por ejemplo, presentó en 1940 un proyecto para el area de Cortesella, aprovechando que $e$ blan Regulador de Como de 1937 prevela el dernbo de buena pante de las manzanas medievales edficadas soplazas aceptando el tejido ortogonal del castro original ${ }^{13}$. Articulaba piezas de diferente longitud, según se fueran

encontrando con la edificación existente, paralelas con orientación norte-sur, y que contenían oficinas y una plaza cubierta, con un cine y un hotel, accesibles desde la calle. sobre este sistema, ruzándolo transversalmente, sobrepuso una última pieza este-oeste de varias plantas, que Año Años después, en 1961 y en un lugar menos exigente. un poligono terciario de la periferia del norte de Múnich Wassili Luckhardal planteó un edificio para la asistencia social de la administración bávara con el mismo concepto que Terragni (figura 4). . Finalmente, fue el proyecto que Van den Broek y Bakema construyeron pocos años tura de

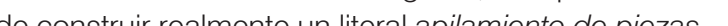

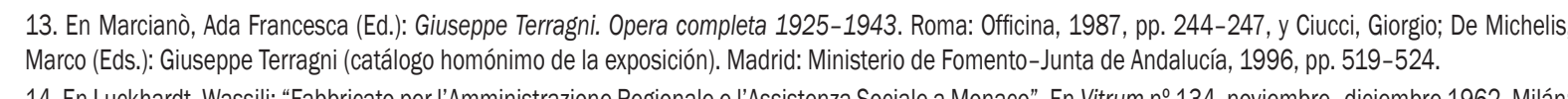

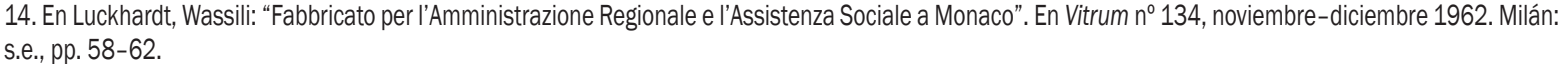
15. En Joedicke, Jürgen (Ed.): La comunidad de arquitectos Van den Broek/Bakema. Barcelona: Gustavo Gili, 1978, pp. 70-77.

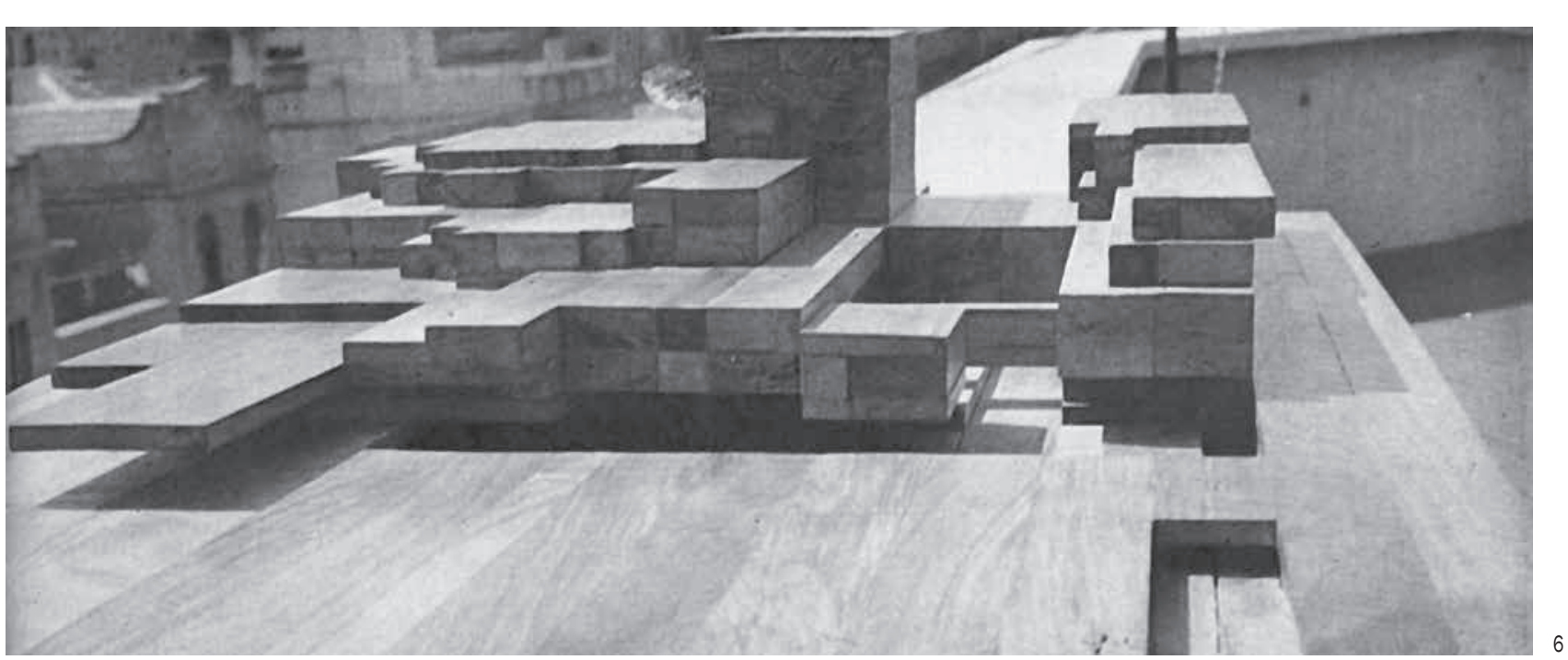

En España, como ejemplo de gran literalidad, el equipo constituido por Corrales, Molezún de la Sota, Garcí de Paredes y Aranguren presentó el proyecto para el coneta (figura 6) que también acumulaba y supernonía piezas de madera Sin embargo, al distinguirse las realizadas con posterioridad una vez dibuiado el proyecto, quedaba demostrado que el juego, en esta ocasión, buscaba una forma en cierta medida predeterminada ra hasta hoy. Después de que Steven Holl remitiera tan directamente su proyecto de Phoenix' ${ }^{16}$ a la mencionada "construcción de distancias" de Rodchenko, lo que de manierista epígono de esta moderna veta constructiva pudo suponer hace unos años la Biblioteca Central de Seattle de Rem Koolhaas ha quedado rápidamente replicado por la similitud de las estrategias empleadas en algunas penúltimas obras de Kazuyo Sejima, Shigeru Ban y Herzog \& De Meuron: el Museo de Arte Contemporáneo de Nueva York, el Centre Pompidou-Metz y la Vitrahaus en Weil am Rhein, respectivamente. Recordemos que cada una de las cinco plataformas de la biblioteca, tal como las denomino Koolhaas, aloja una parte del programa claramente distinguible de las demás, resueltas todas según sus dimensiones y requerimientos especificos. Esta vez, la estructura de apilamiento quedo encubierta al exterior por una envolvente de curso del palacio de la Ópera de Madrid con una maqu-

Es esta una línea de investigación formal que perdu-

vidrio, tensada al máximo -siendo esta la única diferencia respecto a la morbida de Ban-, que forra la irregular volumetría que marcan de arriba abajo las aristas de las disímiles plataformas Sin esta piel, que reviste escultóricamente la expresiva solución del apilamiento el edificio ofrecería sin más la estricta superposición de sus cinco piezas

FISAC: "UNA CIERTA SINGULARIDAD"

De sobra son conocidas las particulares vicisitudes de la arquitectura española y las oscilantes relaciones que propiciaron con las arquitecturas europeas y americanas a lo largo del siglo pasado. En concreto, la pujante generación ágrafa, como la calificó Juan Daniel Fullaondo, retomo como pudo los aires de una modernidad sumida entonces en un "tiempo de estupor". Sus arquitectos fueron picoteando de donde mejor creyeron y pudieron, distanciados por nuestro particular "tiempo de silencio" sin que mediase poco más que su ilusión y entrega. Sólo hace falta recordar cuanto suponían en aquellos anos un viaje o unas revistas. El construir, para ellos, validaba cualquier referencia, por improcedente o extraña que fuera - Inesperadamente, la absoluta singularidad que presenta alguna Innea seguida por Miguel Fisac, uno de los econocidos maestros de dicha generación, tiene una evi政 absolutamente propia de la modernidad del siglo pasado.

16. Holl, Steven: “Spatial Retaining Bars. Phoenix, USA". En El Croquis n 7 78, 1996. Madrid: El Croquis, pp. 66-69.

17. Véase, por ejemplo, Koolhass, Rem/OMA: 2Biblioteca Central de Seattle". En EI Croquis n $134 / 135,2007$. El Escorial: El C roquis, pp. 62-117. 18. Aśl los calificaron Valeriano Bozal en la introducción de su libro homónimo sobre el arte europeo de possuerra, y Luis Martin-Santos en su única novela. :El tiempo del estupor. Madrid: Siruela, 2004, p. 13, y Martin-Sant 1946, con sus primeras viviendas unifamililares experimentales, de marcado experimentales de Puerta Bonita. En el tercer tipo de 1946 ya es perfectamente identificable la vivienda como un sistema de tres crujuas paralelelas definidas por muros de carga, que también comienzan a expresarse en el exterior, quebrando su perímetro, desfasadas entre si 
En la obra de Fisac, y desde bien temprano -puesto que ya se puede rastrear en los mecanismos de adición de sus proyectos de Casas en cadena'19, toda una coumna sin fin, en terminos brancusianos, tendida sobre e suelo-, se puede seguir su interés por proponer volúmenes apilados, con variados desilzamientos más o menos pronunciados entre ellos. Si en todos sus repetidos proyectos de vivienda social de los anos cincuenta la suma de las sucesivas crujias delimitadas por los muros de carga normales a fachada pudiera pensarse como esa columna horizontal, ipor qué no enderezarla y pensar que, siendo ahora los planos de deslizamiento forjados, lambién se podria considerar algo semejante en altura, con plantas superpuestas no coincidentes? "La solución proyectada creaba unos corrimientos alternativos de cada planta respecto de la anterior", explica en alguno de los proyectos consultados.

Si el escultórico modelado que le permitieron materiales tan reiteradamente utilizados por él, como el ladrillo y el hormigón -bien patente, por ejemplo, en la colección de iglesias que suponen las de Escaldes, Alcobendas, Malaga, Vitoria, Madrid, Oleiros....-, pudiera acercarlo a los presupuestos escultoricos del pajaro brancusiano, no es menos clerto que los sistemas de adiciones utilizados por Fsac a lo largo de los anos sesenta también habilan generado una sene completa de obras y proyectos que de de la repelliva colu co desciltor la más periza Casa de propia co nán

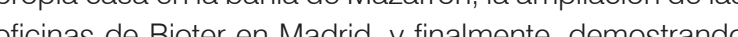
ave fue uno de sus temas recurentes, las oficinas de que fue un de sus temas De momento, resulta sintom

- útimo de todas estas disquático que el sentido ullino de todas estas disquisiciones haya consque Fisac repetín en las memorias de sus proyectos Siguiendo un patrón predeterminado de epígrafes tod ellas en función del tamaño y compleijdad del edificio rellenan con variable profusión de datos el titulado "Criterio

general de composición del edificio, sistema constructivo yonsideraciones teónicas generales. Titular ast un ep grafe de la memoria de un proyecto comporta una definición muy precisa de intereses, que son precisamente Ios que atiende este trabajo: forma, construcción, teoría. En la Memoria de la Casa de la Cunura do Cuenca presentada a visar con fecha de mayo de 1958, meses después de haber finalzado el que hoy entenderiamos como proyecto básico, Fisac asocia en el enunciado del segundo epigrafe cuanto hemos venido planteando. Obviamente, no profundiza en dicha relación, limitándose a explicar, después del programa de necesidades y su desarrollo en el proyecto -y con el mismo agrio tono de tantas veces-, la razón del llamativo vuelo del cuerpo superior que caracteriza la obra: "Es una pena que una concepción ramplona de un urbanismo trasnochado no nos haga posible jugar con la adaptación al terreno de tan glonisa lradición en Cuenca, teniendo que someternos a la vilgar ubicación del edificio en un solar plano entre ca lles que nos impone la urbanización del solar de que dis-

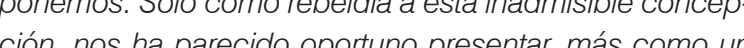
cion, nos ha parecido oportuno presentar, más como un zona colada . Estudios Conquenses"2o. Antes de quesina a Centro y un no sé qué" comenzara a de que su recurrente .... y un no se que comenzara a servile para dar cabida a cuanto escapaba (y trascendla) en su arquilectura a estar movido por otras. Tal como Yves Klein se declo dicho la subtivar la fotografia de su salto. Fisac se presento "qu' "figutivo realista y no abstrocto", Quiso una casa (de laulura y realsta, y no abstracto . Quiso una casa Desde el verano de 1965, también sabí perfectamente cómo qué́ que fuesen los laboratorios Jectaque le habín sido encargados, aunque avanzara sin dar aún con el remate adecuado a lorre que se asoma a la carretera de salida hacia Barelona Desde los primeros dibuios hasta la Memoria del projecto de norem su coronacín, Fisac imagina las sucesivas plantas

20. El expediente de la Casa de la Cultura de Cuenca figurara registrado con el número 37 en el archivo de Miguel Fisac. Como se sabe, guardaba los planos originales de sus proyectos colgados de perchas autofabricadas en armarios inicialmente temáticos, aunque siempre conservaba un ejemplar de cada proyecto encarpetado y visado. Las sucesivas Memorias citadas han sido consultadas en estos ejemplares
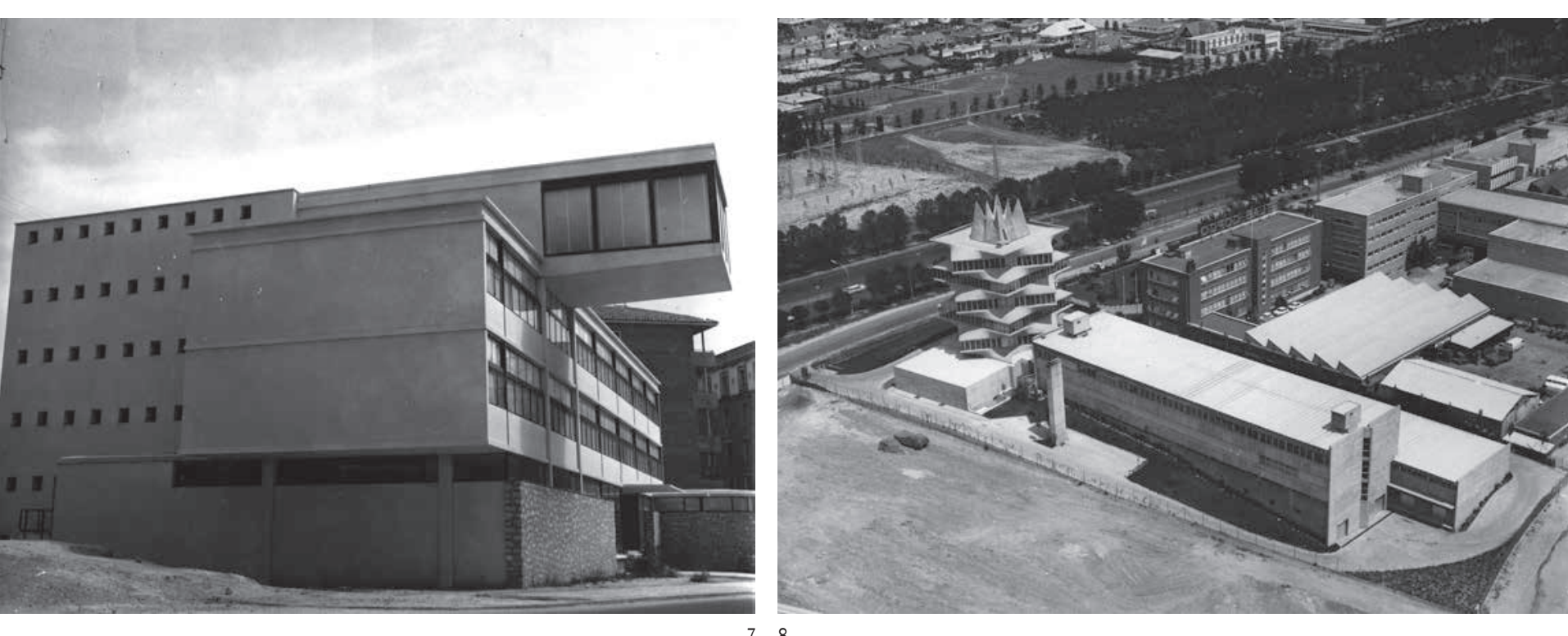

superpuestas, pero girando todas $45^{\circ}$ respecto de inmediata inferior Un apilamiento de bandejas de geometrías más rotundas que los suaves e inquietantes deslizamientos entre plantas que Mario Ridolfi dibuió para la Torre de los Restaurantes de Terni y la del Motel Agip de Settebagni, influida esta última, tanto como la de Fisac settebagni, inlu " a estopista de Barajes", por su posición en el nudo del Grande Raccordo Anulare de Roma? De nuevo, la Memoria del proyecto de Fisac, además de referirse a las partes puestas en juego, incluía un ingrediente nuevo: "Tiene en cada una de sus partes la grediente nuevo: "Tiene en cada una de sus partes la zar los diferentes trabajos de forma óptima, y asi desde la entrada de materias primas y envases, los productos recorren un itinerario ininterrumpido de mínimo recorrido y fáciles transportes, tanto verticales como horizontales, hasta su salida de los almacenes y de la zona de empaquetado y embalaje. (...) Estéticamente se ha procurado que todo el conjunto tenga una unidad plástica tanto por la homogeneidad del material como por la continuidad de todas las lineas horizontales que cierran el conjunto. Hay, sin embargo, un elemento notable resaltado en forma de torre, que se destina a oficinas, dirección, biblioteca, etc., que al crear una alternativa disposición volumétrica de sus plantas, cuadradas de $16 \mathrm{~m}$ de lado, giradas con respecto a la anterior $45^{\circ}$ y enlazadas con paraboloides

hiperbólicos que ocupan los antepechos de una planta y L a inferior producen un juego de vo muy característico a manera de distintivo publicitario de los laboratorios"22 (figura 8)

El alarde del encofrado de la "membrana de hormigón" -así la menciona en la Memoria- formada por los paraboloides, dándole así una sorprendente continuldad, le permitió superar los ineludibles problemas de cortante que, recordemos, el equipo de Terragni había legado a dibujar al pretender asomar al Duce a la Vía del Imperio "cortando" la fachada en la propuesta A del concurso del Palacio del Littorio. Las cerchas mealicas emergentes en la cubierta y no visibles desde abajo, junto a la hendidura vertical preparada para la Irrupción del palco del duce, producían un enigmático diagrama grabado en el muro, reflejo de la tradición romana de estructura vista revelando sus tensiones internas, tal como sucede por ejemplo en los arcos de descarga de los muros exteriores de ladrillo del Panteón La estructura representaba también asi los aspectos simbolicos del edificio, proponía una representación bidimensional de fuerza mostrando la potencia e importancia del nuevo monumento en relación a los de los Foros 29 Igual que la volumetria obtenida para los laboratorios con estos giros convertía el edificio en su mejor "distintivo pu-

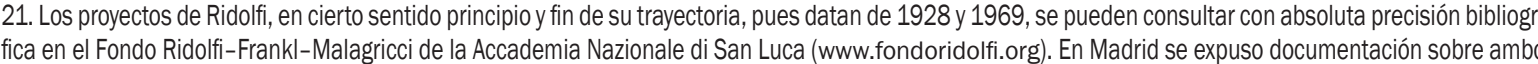
en la sala de las Arquerías de los Nuevos Ministerios. Vease el catálagogo de la misma: Sánchez Lampreave, Ricardo (Ed).): Mario Ridofi. Arquitecto (1904-1984). Madrid: Ministerio de Obras Publicas y Transpootte/Roma: Accademila di San Luca, 1991

政

23. Véase Tafuri, Manfredo: "Il sogrgetto e la maschera”". En Lotus international n 20, septiembre 1978. Milán: Electa, pp.4-31. 
9. Plantas del "Proyecto de chalet para D. Miguel Fisac en Bahía de Mazarrón (Murcia)", diciembre

10.Alzados
bre 1968.
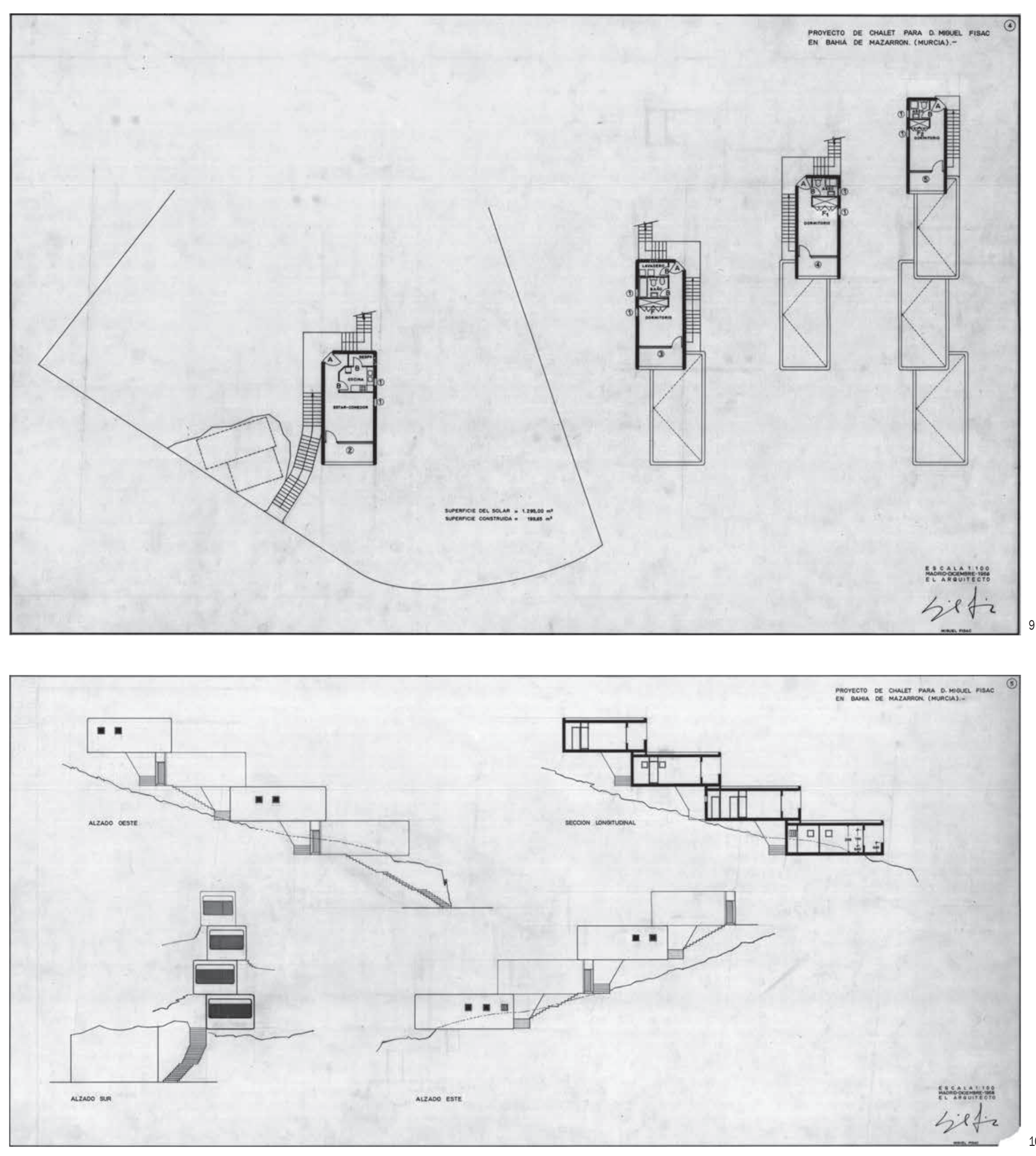

Prueba de su interés por avanzar en esta línea, pues mientras construía los laboratorios decidió hacerse alli samente en este tipo de formalizaciones, a pesar de la opografía de la parcela, las limitaciones del programa y las condiciones de la normativa, o quizás por todo ello. Esta vez la Memoria será estrictamente descriptiva, sin bles, quizás por no tergumento más que los imprescinduna ladera rocosa, de unos $30^{\circ}$ de inclinación, con vistas hacia el mar. Se trata de edificar una pequeña vivienda con una disposición y calidad de materiales muy modesta, en que las allerentes piezas de que consta la casa están tomadas por cuarro módulos que van disminuyendo de lamaño y que se van apoyando cada uno en el anterior" (igura 9). En su senciliez y elementalidad, como si de autenticas plezas de Froebel se tratara, el interés de Fisac por obtener la forma del edificio apilanndolas queda 位encia. De cajones hablaba el. Porque tal como demuestran sobradamente numerosos ejemplos de arquilectura moderna, una cosa es adaptarse a una acusada pendiente -sin que le resultara suficiente la exisente, debiendola aumentar con el recortado cuerpo bajo sobre el que las va depositando (figura 10)-y oira distinta querer dejar desplazados en ambas direcciones los sucesivos volumenes a superponer, como si hubieran sido depositados unos sobre otros sin mayor esmero. Seguramente, tampoco fuera ajeno Fisac a ciertas propuestas Safdie para el Hábitat de Montreal.

Poco despues, apenas unos meses, ya en 1969 Fisac recibió el encargo de ampliar los laboratorios Bioer situados en el lado opuesto de la misma salida de Barcelona de los Jorba, una vez pasado el puente de la Cea en el cruce con la calle Arturo Soria. Esta vez, con un explicito requerimiento de la propiedad: que el edificio tuviera una cierta singularidad (figura 11). En la Memoria de octubre, describe la forma propuesta desde su construoción: "Se ha unlizado un póntico simetrico con voladizos al que alternativamente se va aplicando el cerramiento

una vez en un extremo con el cerramiento opuesto junto a los pilares, invirtiendo en el siguiente este ritmo, con lo que se consigue una disposición alternativa de tensiones tanto en los paramentos laterales como en el paramento apuntado central que además queda patentizado por la linea de forjado de hormigon visto sobre el que se coloca cerramiento de ladrillo correspondiente"

Aunque allineados frente a la autopista y no dispuesos transversalmente a ella, la articulación de la ampliación respecto del edificio existente repetía el esquema de cos Jorba, igual que la continuidad del material, en este caso el ladillo, con los lenguajes que su empleo propicia. En los Bioter, la singularidad" queda conferida, como la "publicidad" en los Jorba, a uno que se eleva algo más queriendo presentarse como una pequeña torre.

La propledad decidio diferir su consirucción y en 1972 , cuando se retomo el proyecto, Fisac ya estaba trabajando en orras soluciones constructivas. Habia terminado elCentro de Rehabillación de la MUPAGy su nuevo cstudio en elceno del Aire, y ya estaba trabajando en la casa de Pascual de Juan en La Moraleja. Reconsidera las caracteristicas del edificio, convence a la propiedad, y argumenta cn una nueva Memoria, queriendose distan"Al realizar la obra en época muy posterior y reconsiderar las caracteristicas esteticas que podria tener este nuevo alifio, que tiene puntos de vista completamente desligacos de la constrccion anterior, se ha pensado en la converien perefrabicado de hormigón con moldes tlexibles, segun parte del arquilecto autor del proyecto, as/ como la sus-

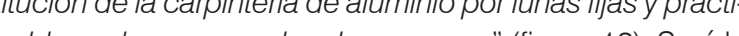
(chera la (lo Uas Jos para dar forma a los paraboloides hiperbólicos de los ses e inclinados, doblándolos suavemente.

Sin embargo, tampoco fue esta la solución definitiva. La constructora elegida por la propiedad puso tantas 

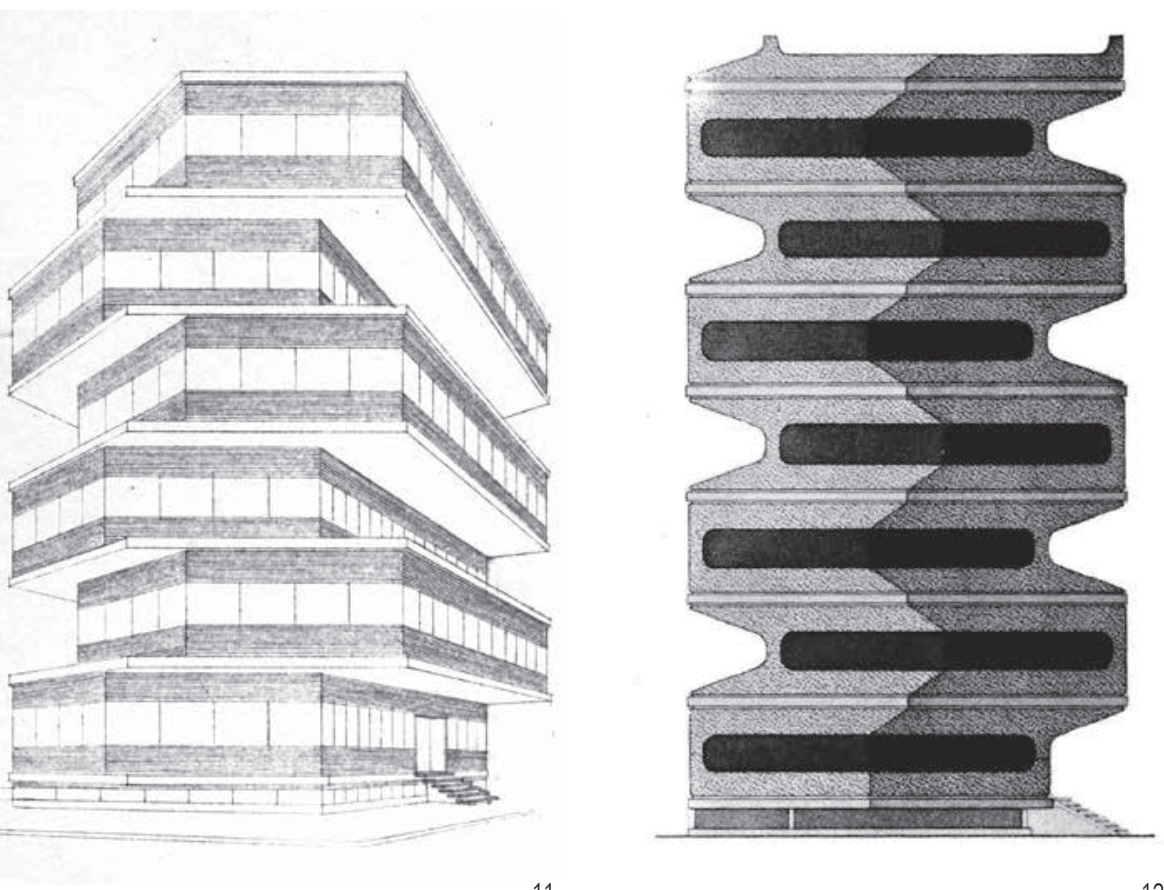

11. Croquis del proyecto de ampliación de las oficinas de Bioter en Madrid, 1969.

(2. 13. Alzados del mismo, mayo 1973.

14. Planta tercera del "Proyecto de Ejecución y ampliación de edificio para oficinas propiedad de la Caja

dificultades a la solución propuesta por Fisac que terminó ofreciendo una solución con chapas onduladas de herro galvanizado sin pintar (figura 13). Por la dificultad hace más que subrayar la indisoluble relación entre formay material, entre forma y construcción-, la disposición de plantas alternativas quedó finalmente sustituida por de plantas alternativas quedó finalmente sustituida por
plantas simétricas respecto al eje longitudinal, de mayor y menor superficie, manteniendo, esto sí, las lunas de vidrio recercadas con juntas de neopreno. Una solución que terminó palideciendo las desconocidas primeras que terminó
propuestas.

Finalmente, en 1988, en la segunda fila de la playa de San Juan, en la Avenida de la Costa Blanca, Fisac tiene ocasión de proyectar un pequeño edificio de oficinas tíá du Caja de Ahorros del Mediterráneo, que le permiAnimado sin duda por a privilegiada posición del sol. en la pra de La Coruña vuelve a utilizar el mismo socur so compositivo, que calfica esta vez de "formalismo escultórico", con una inusitada libertad, presentando unas plantas de geometra varable dictada por la curviliea de pla rotonda (igur 13): "Es, por tonto, un emphzame singular pero que por ordenanza y supericie tiene mecho menos volumen que todos los edificios que le rodean.

Para conseguir una cierta relevancia en el paisaje urbano parece necesario utilizar un cierto formalismo escultórico que, al quedar un poco al margen de la tipología arquitectonica en el que está integrada, pueda presentar ciertos Espectos de contraste

Ento. Irregulares prismas, que pivotan sobre el eje de el ciedro ciego más ale laza, ofrecen, allemalivamente -como sempre habca pretendido hisac en sus aplamientosn el plano de fachada o retanqueads, de toma que, en hormićn y opacos serán de phas prefabricadas de homigún ros zacas con encofrado flexible petente del autor (., ) Las tonalidades de los vidrios no transperentes, asícomo las piezas prefficadas de hormigón serán en tonos chos de a pre n ma ces arenos propios de los paisajes urbanos cerantinos". Una ambigua solución que muestra un desconocido Fisac de anhelos manivistas Las pizas apitadas, ison op cas? itransparentes? iSon de hom migón o de vidrio? Evidentemente, de "lo uno y lo otro", como defendía Venturi y as' lo demuestra el cuidado mostrado en la solucic

26. Desde 1988, Fisac y a no tiene trabajo. Tiene 75 años y apenas registra en su archivo dos expedientes anuales (1988: 366 y 367 . 1989: 368 y $369 . .$. S presencia en Alicante facilita que le encarguen la rehabilitación de una casa antigua (369), la redacción del PAU 4 de Alicante (370), el parque urbano que contiene (371) y sus edfificios auxiliares (372).

27. El expediente de las oficinas para la Caja de Ahorros del Mediterráneo figurar registrado con el número368 en el archivo de Miguel Fisac.
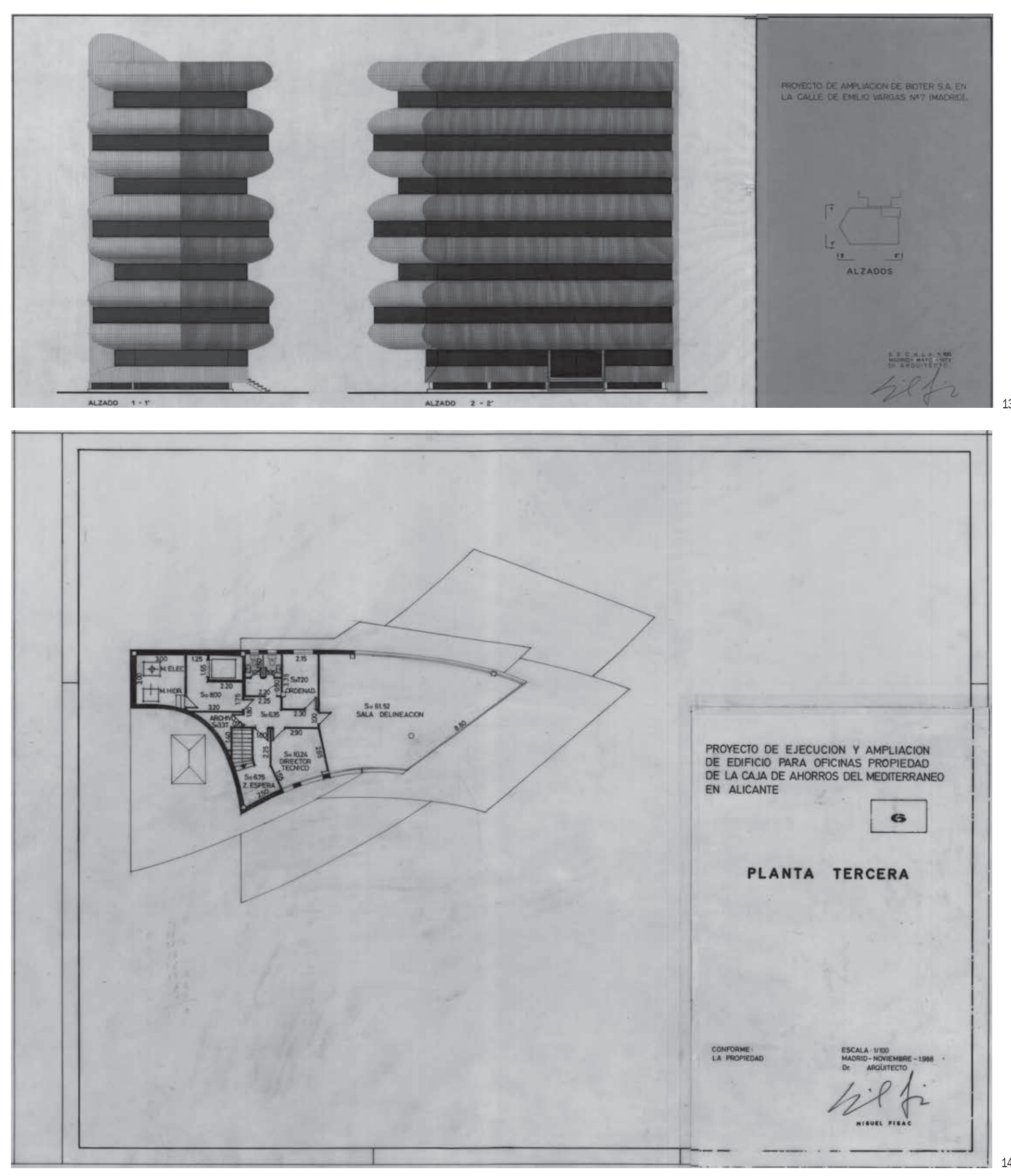


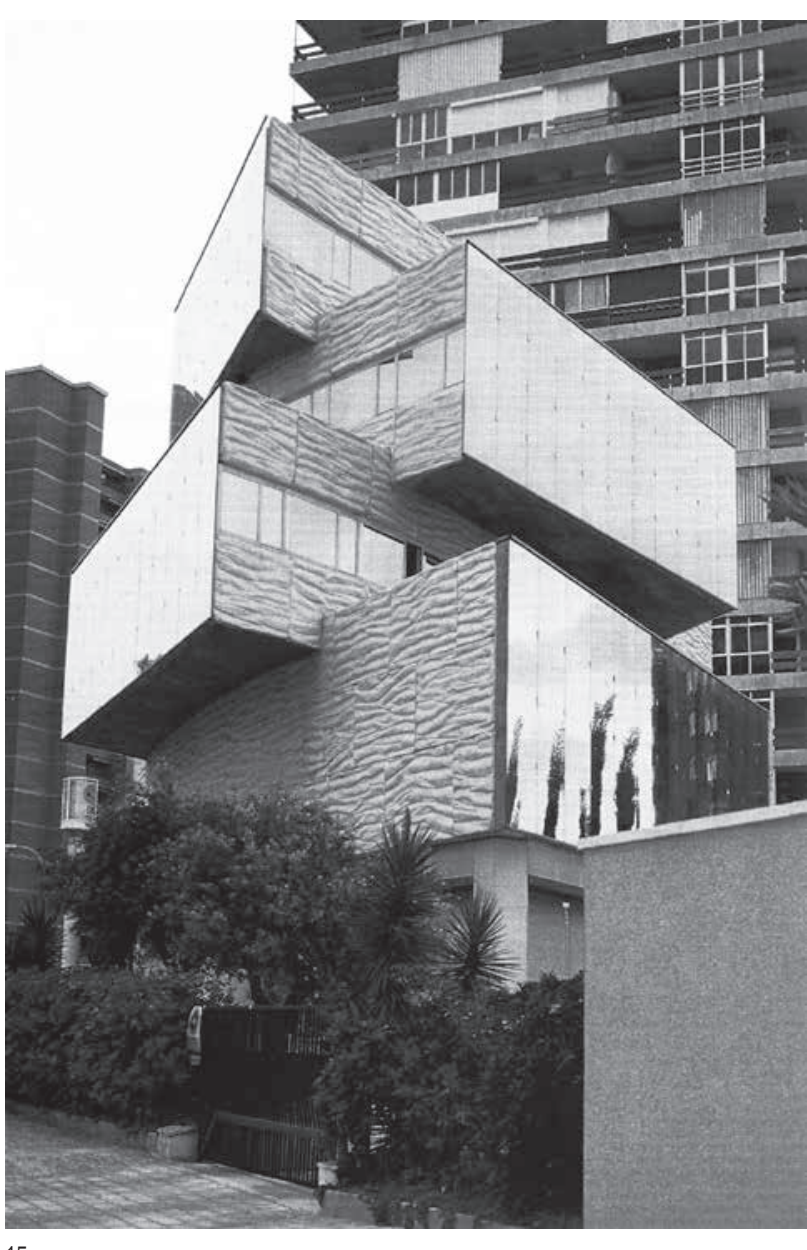

las de hormigón, ¿por qué prefieren rasgar las ventanas de un extremo a otro forzando encuentros entre vidrios en vez de recortar en su masa los huecos necesarios? Y los aleatorios dibujos de la arena, ¿no restan también pesadez a un indisimulado aplacado condenado a mostrarlos discontinuos e inconexos? Entonces, ¿pesan tanto estas piezas como para presentarse hundidas unas sobre otras, esta vez en un descuidado detalle? (figura 15) Esta manera tan característica de Fisac, siempre tan directa, queda lejos la coherente sofisticación mostrada por Luigi Moretti en el milanes Corso Italia. La intervención, cinco edificios de alturas de programas y características diferentes, ocupa un solar irregular que se asoma con forma de cuña, al Corso ${ }^{2}$. La interpretación urbana de Moretti es la de una gran máquina donde se desarrolla un itinerario en el que se olvida y se pierde pronto la posibilidad de un entendimiento global. Y no lo es tanto por las diferentes configuraciones otorgadas a los cuerpos de oficinas y viviendas como por la complejidad de as relaciones entre los edificios y el plano del suelo. Lo que en otros pasa por ser una superposición de prismas indiferentes a la operación a que son sometidos, en Moretti, en concreto en la proa del Corso ltalia, se convierte en un esforzado encuentro donde la forma del volumen inferior acaba acusando expresivamente la carga que soporta. Late alli, en aquel tajamar a la calle, quizás en todo vuelo tan acusado, la ansiedad por aprehender un espacio presente -terriblemente presente, la vida delante-que se escapa por ser ya inaccesible para el edificio terminado. "Para pintar el espacio, debo rendirme en el lugar, en ese mismo espacio". Directamente, una ansiedad que emite de nuevo al mascarón en que quiso convertirse Yves Klein en su afán por arrojarse a ella

Por tanto, quizás también discurra por la obra de Miguel Fisac una veta formal representada por la adición y el apilamiento de piezas, fragmentos concebidos tantas veces por separado. Quizás tanto como por la de Constantin Brancusi, capaz de compaginar desarrollos tan depurados y sutiles para obras unicas como sus pajaros en el espacio con los más toscos de su repetida columna sin fin, involuntario fruto de los mencionados "arreglos" "Es signilicalivo que Brancusi estuviera obsesionado toda su vida por to que el llamaba 'esencia del vuelo'. Pero es exraordinario que lograra expresar el impulso ascensional utilizando el arquetipo mismo de la gravedad, la materia por excelencia. la pleclia. Casi podria decirse que realizo una transmulacion de la 'materia', o con mayor precision. que ejecuto una coincidentia oppositorum, pues en el mismo objeto coinciden 'materia' y 'vuelo', la gravedad y su negación. Materia y vuelo fueron, para un estudioso de la historia de las religiones como Mircea Ellade, los terminos que explicaban a su compatriota Brancusi. Quizás tambièn podría haber merodeado con ellos estas singulares obras de Miguel Fisac. $\square$
Aloosin, Anthony: Frank Lloyd Wright. The Lost Years, 1910-1922: A Study of Influence. Chicago: University of Chicago Press, 1993.

Baker, Geoffrey: Frank Lloyd Wright. Madrid: Adir Editores, 1980 .

Bordes, Juan: La infancia de las vanguardias. Sus profesores desde Rousseau a la Bauhaus. Madrid: Cátedra, 2007

Bozal, Valeriano: El tiempo del estupor. Madrid: Siruela, 2004 (PMid:15388704).

Bucci, Federico: Mulazzani Marco: Luigi Moretti. Works and Writingss. Nueva York: Princeton Architectural Press, 2002 Capitel, Antón: Alvar Aalto. Madrid: Akal, 1999

Chan-Magomedov, Selim Omarovich: NikolajLadovskij. Un'ideologia del razionalismo. Lotus International n² 20, septiembre 1978. Milán: Electa. Ciucci, Giorgio; De Michelis, Marco (Eds.): Giuseppe Terragni (catálogo homónimo de la exposición). Madrid: Ministerio de Fomento-Junta alucía, 1996 (PMCid:145640).

Eliade, Mircea: El vuelo máǵico, yotros ensayos. Madrid: Siruela, 2000.

González García, Ángel: "La zanja luminosaa”. En Arnado, Javier et alt:: ¿Qué es la escultura moderna? Del Objetto a la Arquitectura. Madrid: Fundación

Gregh, Eleanor: The Domino Idea. Oppositions n 1 15/16, invierno/primavera 1979. Nueva York: Institut for Architecture and Urban Studies IAUS. Hersey, George: Architecture and Geometry in the Age of the Barooue. Chicago: University of Chicago Press, 2000. Holl, Steven: “Spatial Retaining Bars. Phoenix, USA". En EI Croquis n ${ }^{\circ} 78,1996$. Madrid: El Croquis.

Joedicke, Jürgen (Ed.): La comunidad de arquitectos van den Broek/Bakema. Barcelona: Gustavo Gili, 1978. Koolhaas, Rem/OMA: "Biblioteca Central de Seattle". En El Croquis no 134/135, 2007. El Escorial: El Croquis. Le Corbusier-Saugnier: Vers une architecture. Paris: Les éditions G. Cres et Cie, 1923.

Le Corbusier et Pierre Jeanneret. Oeuure complète. 1910-1929. Zứrich: Les Éditions d'Architecture, 1974. Luckhardt, Wassili: "Fabbricato per 'Amministrazione Regionale e I'Assistenza Sociale a Monaco". En Vitrum no 134, noviembre-diciembre 1962

.

Martín-Santos, Luis: Tiempo de silencio. Barcelona: Seix Barral, 1962.

Muñoz, María Teresa: "La ética contra la modernidad". En Arquitecturas bis n 27, marzo-abril 1979. Barcelona: La Gaya Ciencia Pehnt, Wolfgang: "Gropius romantico". En Rasseǵna n” 15, septiembre 1983 (Walter Gropius 1907/1934). Bolonia: CIPIA.

Rodchenko-Stepánova. Todo es un experimento (catálogo homónimo de la exposición). Madrid: Fundación Banco Central Hispanoamericano, 1992. Sánchez Lampreave, Ricardo (Ed.): Mario Ridoff. Arquitecto (1904-1984). Madrid: Ministerio de Obras Publicas y Transporte. Roma: Accademia

Tafuri, Manfredo: " "I soggetto e la maschera" En Lotus international n²0, septiembre 1978. Milán: Electa.

Wright, Frank Lloyd: Autobiografifia 1867 [1944]. El Escorial: El Croquis, 1988.

Ricardo Sánchez Lampreave (Madrid, 1957). Arquitecto por la ETSAM-UPM en 1983, se doctoró en la misma (2007) con un tesis sobre la aroutectura madrileña de los años '50. Profesor titular de Composición Arquitectónica en la Escuela de Insenierí y A quitectura de la Universidad de Zaragoza, tras serlo de Historia del Diseño Grático en la Universidad Complutense de Madrid (Facultad de Bellas Artes, 1987-1989) y de Proyectos Arguitectónicos desde 1991 hasta 2010 en las Escuelas de Arquitectura de Madrid y de Alcalá de Henares. Fue pensionado en la Academia Española de Roma en 1990-1991. Es patrono de la Asociación Española para la Protección del Patrimonio Arquitectónico del siglo XX AEPPAS20, y fue director de la Fundacion Miguel Fisac desde su constituccion (2007-2009). Ha comisariado diferentes exposiciones (EI suelo en renuncio, Lápices ratones brújulas, Circulos imperfectos, Las otras Grandes Vías), y ha dirigido las revistas BAU, Transfer y Formas, habiendo pertenecido también a varios Consejos de Redacción. 


\section{Autor imagen y fuente bibliográfica de procedencia}

Información facilitada por los autores de los artículos: página 29, 1 (Canogar, Daniel: Ciudades efímeras. Exposiciones Universales: Espectáculo y Tecnología. Madrid: Julio Otero, 1992); página 30, 2 (Der Baumeister, vol. 29, № 7. Julio 1931. München: Verlag Georg D.W. Callwey); página 32, 3 y 4 (McQuaid, Matilda: Lilly Reich. Designer and Architect. New York: Museum of Modern Art, New York. Distributed by Harry N. Abrams, INC., 1996), 5 y 6 (Von Ursel, H. \& Pavel, T: Barcelona Pavilion. Mies van der Rohe \& Kolbe. Architecture \& Sculpture. Berlin: Jovis Verlag, 2006), página 34, 7 (The Mies van der Rohe Archive. Part I, 1910-1937. Vol. 1. New York: Garland, 1986), 8 (Revista 2G. "Mies van der Rohe. Casas". No 48-49. Barcelona: Gustavo Gili, 2009); página 35, 9 (The Mies van der Rohe Archive. Part I, 1910-1937. Vol. 1. New York: Garland, 198), 10 y 11 (McQuaid, Matilda: Lilly Reich. Designer and Architect. New York: Museum of Modern Art, New York. Distribued by Harry N. Abrams, INC., 1996); página 36, 12 (Departamento de Arquitectura del The Museum of Modern Art, The Mies van der Rohe Archive, New York), 13 y 14 (Der Baumeister, vol. 29, № 7. Julio 1931. München: Verlag Georg D.W. Callwey); página 37, 15 (Derecha; AAVV: Mies in Berlin. New York: Museum of Modern Art. Distributed by Harry N. Abrams, INC., 2001. Izquierda; McQuaid, Matilda: Lilly Reich. Designer and Architect. New York: Museum of Modern Art, New York. Distributed by Harry N. Abrams, INC., 1996); página 44, 1 y 2 (AA. W.: Mies in Berlin. New York / Berlín: MoMA, 2001, p. 175, figura 36 y p. p. 169. figura. 25); página 45, 3 y 4 (Schulze, Franz (ed); Darforth, George E. (ed. consulting): The Mies van der Rohe Archive". New York: Garland, 1986-1992, volumen 1, p. 86 y volumen 1, p. 91); página 46, 5 y 6 (Schulze, Franz (ed); Darforth, George E. (ed. consulting): The Mies van der Rohe Archive". New York: Garland, 19861992, volume 1, p. 288 y volume 1, p. 183); página 46, 7 (AA. W.: Mies in Berlin. New York / Berlín: MoMA, 2001, p. 97); página 48, 8 a 10 (Schulze, Franz (ed); Darforth, George E. (ed. consulting): The Mies van der Rohe Archive". New York: Garland, 1986-1992, volumen 20, p. 300 y p.122); página 48, 11 a 13 (Schulze, Franz (ed); Darforth, George E. (ed. consulting): The Mies van der Rohe Archive". Nwe York: Garland, 1986-1992, volumen 4, p. 390, p. 415 y p. 393); página 50, 14 y 15 (Schulze, Franz (ed); Darforth, George E. (ed. consulting): The Mies van der Rohe Archive". Nwe York: Garland, 1986-1992, volumen 4, p. 389 y p. 75); página 56, 16 (Schulze, Franz (ed); Darforth, George E. (ed. consulting): The Mies van der Rohe Archive". Nwe York: Garland, 1986-1992, volumen 4, p. 78); página 59, 1 (Bloc, André: De la sculpture a l'architecture. Boulogne (Seine): Editions Aujourd'hui, 1964. p. 100) ; página 61, 2 (Bloc, André: De la sculpture a l'architecture. Boulogne (Seine): Editions Aujourd'hui, 1964. p. 101), 3 (Amon, Santiago:"La exaltación del orden artificial en la arquitectura de Parent y Bloc". En Nueva Forma. Marzo de 1967, № 50. p. 4); página 62, 4, 5 y 6 (Bloc, André: De la sculpture a l'architecture. Boulogne (Seine): Editions Aujourd'hui, 1964. p. 96, p. 93 y p. 95 ); página 64, 7, 8 y 9 (Bloc, André: De la sculpture a l'architecture. Boulogne (Seine): Editions Aujourd'hui, 1964. p. 97 y p. 100); página 68, 10 (Migayrou, Frédéric: Bloc Le Monolithe Fracturé. Orléans: Éditions HYX, 1996. p. 30), 11 (Héctor GarcíaDiego Villarías, María Villanueva Fernández), página 70, 12 (Héctor García-Diego Villarías, María Villanueva Fernández); página 74, 1 (Lipman, Jonathan: Frank Lloyd Wright and the Johnson Wax Buildingss. New York: Dover Publications, 2003. Republicación de la edición original de Rizzoli, 1986. p. 60); página 75, 2 (Signatura 12-154 OCSIC, Instituto de Ciencias de la Construcción Eduardo Torroja (IETcC)), 3 (Architectural Forum. Vol.102. No5. Mayo 1955. p. 86); página 76, 4 (Signatura DIBZ-058 Fondo Zuazo. Biblioteca Nacional de España), 5 (Víctor Larripa Artieda); página 78, 6 y 7 (Víctor Larripa Artieda); página 80, 8 y 9 (Signatura DIBZ-058 Fondo Zuazo. Biblioteca Nacional de España); página 82, 10 (Cahiers d’art. 4ème année. No6. 1929. p. 278), 11 (Signatura 11-8 @CSIC, Instituto de Ciencias de la Construcción Eduardo Torroja (IETcC)); página 84, 12 (Arquitectura. № 10. 0ctubre 1959. Madrid: COAM. p. 7); página 85, 13 (Signatura DIBZ-058 Fondo Zuazo. Biblioteca Nacional de España), 14 (Víctor Larripa Artieda); página 86, 15 (Signatura 007F.RET @CSIC, Instituto de Ciencias de la Construcción Eduardo Torroja (IETcc)); página 90, 1 (Thomson, D’Arcy: Sobre el crecimiento y la forma. Madrid: Cambridge University Press, 2003); página 91, 2 y 3 (Cook, Theodore: The Curves of Life. London: Dover Publication, 1979); página 92, 4 (Cook, Theodore: The Curves of Life. London: Dover Publication, 1979), 5 (Ind, Rosemary: Emberton. London: Scolar Press, 1983 ); página 93, 6 (Drexler, Arthur: The drawings of Frank Lloyd Wright. New York: Horizon Press, 19); página 94, 7 (Brooks Pfeiffer, Bruce: Frank Lloyd Wright. Monograph. Tokio: ADA, 1985), 8 (Izzo, Alberto, Gubitosi, Camillo: Frank Lloyd Wright. Drawingss 1887-1959. Firenze: Centro Di Stiav, 1977); página 96, 9 (Levine, Neil: The architecture of Frank Lloyd Wright. New Jersey: Princeton University Press, 1996. Rasmussen, Steen Eiler, Experiencia de la arquitectura. Barcelona: Ed. Labor, 1974); página 97, 10 y 11 (AA.W: The Solomon R. Guggenheim Museum. Nueva York: Guggenheim Museum Publications, 1995$), 12$ (Levine, Neil: The architecture of Frank Lloyd Wright. New Jersey: Princeton University Press, 1996); página 98, 13 (Casto Fernández-Shaw. Arquitecto sin fronteras, 1896-1978. Madrid: Catálogo de la Exposición del Ministerio de Fomento, 1999; Cabrero, Félix: Casto Fernández-Shaw. Madrid: COAM, 1980); página 99, 14 (El Croquis. 1988, № 32-33); página 100, 15 (García-Pola, Miguel Ángel, “Astúries. L'ènica del desenvolupament”. En Quaderns d'Arquitectura i Urbanisme. 1997, № 215; García, Celestino; Agrasar, Fernando: Arquitectura moderna en Asturias, Galicia, Castilla y León. Ortodoxia, márgenes y transǵresiones. COA Asturias; COA Galicia; COA Castilla y León Este; COA León, 1998); página 101, 16 (Peña, Antonio; Díaz, José; Daroca, Francisco (ed.): Rafael de La-Hoz. Arquitecto. Catálogo de obras y proyectos. Córdoba: Demarcación de Córdoba del Colegio de Arquitectos de Andalucía Oriental, 1991); página 105, 1 (Collection George E. Thomas); página 107, 2 (Tribune Company); página 108, 3 (Scott Gilchrist, Archivision Inc.), 4 y 5 (The Frank Lloyd Wright Foundation Archives (The Museum of Modern Art \& Avery Architectural \& Fine Arts Library, Columbia University, New York); página 110, 6 (The Frank Lloyd Wright Foundation Archives (The Museum of Modern Art \& Avery Architectural \& Fine Arts Library, Columbia University, New York)); página 111, 7 (Alfonso Díaz Montes), 8 (Collection Alden Franz Aust); páginas 112 a 114, 9 a 14 (The Frank Lloyd Wright Foundation Archives (The Museum of Modern Art \& Avery Architectural \& Fine Arts Library, Columbia University, New York)); página 115, 15 (Wisconsin Historical Society); página 120, 1 (Rodchenko-Stepanova. Todo es un experimento (catálogo homónimo de la exposición). Madrid: Fundación Banco Central Hispanoamericano, 1992); página 121, 2 (Chan-Magomedov, Selim Omarovich: NikolajLadovskij. Un'ideologia del razionalismo. Lotus International nº 20, septiembre 1978. Milán: Electa), 3 (Nerdinger, Winfried: Walter Gropius. Opera completa. Milán: Electa, 1985; y Giedion, Sigfried: Walter Gropius. L'homme et l'oeuvre. París: Albert Morancé, 1954); página 122, 4 (Ciucci, Giorgio; De Michelis, Marco (Eds.): Giuseppe Terragni (catálogo homónimo de la exposición). Madrid: Ministerio de Fomento-Junta de Andalucía, 1996; y Vitrum n 134, noviembre-diciembre 1962. Milán: s.e.), 5 (Joedicke, Jürgen (Ed.): La comunidad de arquitectos Van den Broek/Bakema. Barcelona: Gustavo Gili, 1978); página 123, 6 (Archivo Corrales); página 125, 7 (Sánchez Lampreave, Ricardo (Ed.): Miguel Fisac. Premio Nacional de Arquitectura 2002. Madrid: Ministerio de Vivienda, 2009), 8 (Arques Soler, Francisco: Miguel Fisac. Madrid: Pronaos, 1996); página 127, 9 y 10 (Sánchez Lampreave, Ricardo (Ed.): Miguel Fisac. Premio Nacional de Arquitectura 2002. Madrid: Ministerio de Vivienda, 2009); página 128, 11 (Sánchez Lampreave, Ricardo. Líneas y abstracciones. Arquitecturas madrileñas de los '50. Director: Gabriel Ruiz Cabrero. Universidad Politécnica de Madrid, Departamento de Proyectos Arquitectónicos, 2007), 12 (Morales Saro, María Cruz: La arquitectura de Miguel Fisac. Ciudad Real: Colegio de Arquitectos de Ciudad Real, 1979 ); página 129,13 y 14 (Sánchez Lampreave, Ricardo (Ed.): Miguel Fisac. Premio Nacional de Arquitectura 2002. Madrid: Ministerio de Vivienda, 2009); página 130, 15 (Arques Soler, Francisco: Miguel Fisac. Madrid: Pronaos, 1996); página 133, 1 (Ingrid Campo-Ruiz), 2 (464 F6, Flygfoto med bladindelning samma som ekonomisk karta. 1969. [Malmö Stadsbyggnadskontorets Arkiv]); página 134, 3 (205E16, Ekonomisk Karta över Sverige, $2 c$ Malmö Bulltofta. 1969. [Malmö Stadsbyggnadskontorets Arkiv]), 4 (Lewerentz, Sigurd: “Betonghus på Östra Kyrkogården i Malmö”. En Arkitektur. Febrero 1973, N² 2. p. 4), 5 (Lewerentz, Sigurd. Kyrkogårdsförvaltningen, Malmö, Byǵgnad för Blömsterförsäljning vid Östra Kyrkogården i Malmö, Stadsäga nr 199 Rosengård. Plan, sektion, fasader \& situat. plan. Malmo, 2 de diciembre 1968. Malmö kyrkogårdsförvaltning F 1Q:26. [Malmö Stadsarkivet]); página 135, 6 (Flygtrafik i Bengtsfors AB: Vista aérea de Rosengård 1970. Negativo. 13,1 x 18,5 cm, 85976_1157_01. [Lund: Archivo de Kulturen]); página 136, 7 (Ingrid Campo-Ruiz), 8 (Lewerentz, Sigurd. Kyrkogårdsförvaltningen, Malmö, Byǵgnad för Blömsterförsäljning vid Östra Kyrkogården i Malmö, Stadsäga nr 199 Rosengård. Plan, sektion, fasader \& situat. plan. Malmo, 2 de diciembre 1968. Malmö kyrkogårdsförvaltning F 1Q:26. [Malmö Stadsarkivet]); página 137, 9 (Ingrid Campo-Ruiz); página 138, 10 (Lewerentz, Sigurd. Östra Kyrkogården i Malmö, Försäljning av Blömmor, Sektion A-A, D-D Skala 1:20 Detaljer 1:1. Skanör, septiembre, 1968. Malmö kyrkogårdsförvaltning F 1Q:26. [Malmö Stadsarkivet]); página 139, 11 (Ingrid Campo-Ruiz); página 140, 12 y 13 (Ingrid Campo-Ruiz); página 142, 14 (Dibujo 1 (arriba): Lewerentz, Sigurd. Östra Kyrkogården i Malmö, Försäljning av Blömmor, Fasad mot söder. Escala 1:20, detalles 1:1. Skanör, 1 de abril, 1969. Malmö kyrkogårdsförvaltning F 1Q:26. [Malmö Stadsarkivet]. Dibujo 2(abajo): Lewerentz, Sigurd. Östra Kyrkogården i Malmö, Försäljning av Blömmor. Escala 1:20, detalles 1:1. Skanör, septiembre, 1968. Malmö kyrkogårdsförvaltning F 10:26. [Malmö Stadsarkivet]), 15 (Ingrid Campo-Ruiz); página 144, 16 (Blomsteraffären [Kyrkogårdsförvaltningen i Malmö]); página 149, 1 (La Vanguardia. Martes 23 de abril de 1968. Barcelona: Grupo Godó, 1968. p. 46); página 150, 2 (La Vanguardia. Viernes 2 de junio de 1972. Barcelona: Grupo Godó, 1972. p. 2); página 152, 3 (“Edificio industrial para Dallant, S.A.”. En Cuadernos de Arquitectura. № 55. Barcelona: COACB, 1964. p. 5); página 153, 4 (Serrano Freixas, Ángel: “Un edificio diseñado: Banca Catalana, de Tous y Fargas”. En Cuadernos de Arquitectura. № 70, Barcelona: COACB, 1967. p. 26); página 155, 5 y 6 (Serrano Freixas, Ángel: “Un edificio diseñado: Banca Catalana, de Tous y Fargas”. En Cuadernos de Arquitectura. № 70, Barcelona: COACB, 1967. p. 28 y p. 29); página 156, 7 (Pizza, Antonio; Rovira, Josep Maria: Desde Barcelona, Arquitecturas y Ciudad: 1958-1975. Barcelona: Collegi d'Arquitectes de Catalunya - Ministerio de Fomento, 2002. p. 175); página 158, 8 (Montaner, Josep Maria: Arquitectura Contemporánea en Catalunya. Barcelona: Edicions 62, 2006. p. 125) 